\title{
Extending Access to Remote Labs from Mobile Devices in Educational Contexts
}

\author{
http://dx.doi.org/10.3991/ijoe.v9iS3.2538

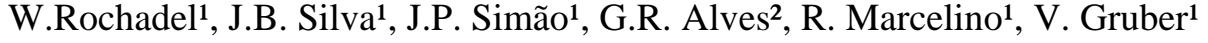 \\ ${ }^{1}$ UFSC, Federal University of Santa Catarina, Araranguá (Brazil) \\ ${ }^{2}$ IPP/ISEP, Polytechnic of Porto, School of Engineering, Porto (Portugal)
}

\begin{abstract}
This paper describes how to extend the access to remote experiments from mobile devices, aiming to better engage digital native students who expect a more interactive and ubiquitous access mode. The extension is based on features of HTML5 and the jQuery Mobile framework, which allow accessing the experiments from different operating systems via the browser or native applications. As a result, users have a richer interaction mode with the experiments, which includes access from simple hand-held devices such as smartphones and PDAs. Extending the access to remote experiments, from simple devices, enables its use in other educational stages, such as high schools, where teachers struggle to engage students in STEM learning. By enabling students to use their everyday "technological companions", e.g. cellular phones, to access remote experiments, we seek to increase the educational value of this technology-enhanced learning resource.
\end{abstract}

Index Terms-Remote Experiments; Mobile Learning; Mobile Experimentation; mobile devices; HTML5 and jQuery Mobile.

\section{INTRODUCTION}

Usability is the ability of a particular product to be used by the individual to achieve specific goals with efficiency and satisfaction in a unique context of interaction [1].

Thus, the relationship between mobility and accessibility becomes an important aspect to be implemented in mobile applications devices. In a pedagogical context this issue conciliates an interesting tool to solve some gaps in the teaching and learning field. As in the technologies and sciences fields that require the realization of experimental work with laboratory equipment and experiments to demonstrate in practice the concepts discussed in class.

The scarcity of these resources, the lack of laboratories and even the difficult access limits a more practical learning. So, when it comes providing a closer-to-reality experience it attracts students by itself. Simulators and virtual labs are used to experience simulated results recorded. But beyond these resources, the use of remote resources tends to allow experience to be even more real [2].

When interacting with experiments in remote laboratories the user has the experience to be working with physical equipment available for researchers which provides an even more enjoyable usability. It is certainly a challenge in creating new experiences. The availability of these resources should be concerned with the easiness provided by operating the experiment from anywhere and at any time, the concept of ubiquity [3].
Thus, by providing a student involvement with remote experiments in his own mobile device expands even further the usefulness of laboratories, because, after all, users are constantly connected to these mobile facilities and can learn, review and demonstrate the science concepts while moving on the way to school, with friends or in the classroom with only one device that allows access to the internet.

This concept extends the use of experiments beyond the laboratory or classroom and provides new users with access to these resources on the bus, the subway, in a taxi, or in rows. Wherever information and appropriate interfaces are essential to meet immediate needs [4].

There is an expansion of the mobile network while mobile devices are becoming more affordable and still have interesting technological features that stand out such as accelerometer, touchscreen, vibration, location and compass. Able to combine these resources with teaching tools they provide a more attractive and dynamic interaction with the student.

Constantly connected, new forms of teaching are not enough to please students. It is not enough to provide access to the same feature that is commonly available and an inadequate mobile reality, every method must converge interactively.

Relatively new, the Mobile Learning (m-learning) [5] needs applications that take advantage of all the technological resources available on a mobile device. What happens are simple adaptations of the pages or applications of workstations, which do not offer an innovative experience in interaction?

The availability of these resources follows international standards that the World Wide Web Consortium (W3C ${ }^{1}$ ) recommends [6] and is based on concepts of Virtual Environments discussed by Pereira [7].

Although they are more accessible, sometimes not all common smartphones have many features or have a lower quality than the more advanced devices.

With these concepts the Remote Experimentation Lab of Universidade Federal de Santa Catarina has developed RExMobile (Fig. 1), an application adapted for the use of remote experiments by different Operating Systems.

This way, RExMobile interface and usability experience tries to provide in its development a simple interactivity, adaptable, and still, offering this involvement with users in a pleasant way.

Another concern about the teaching material available is objectivity, because the user is not usually with the device in hand for long periods and focus, this time is

1 Available at: http://www.w3.org/mobile/ 


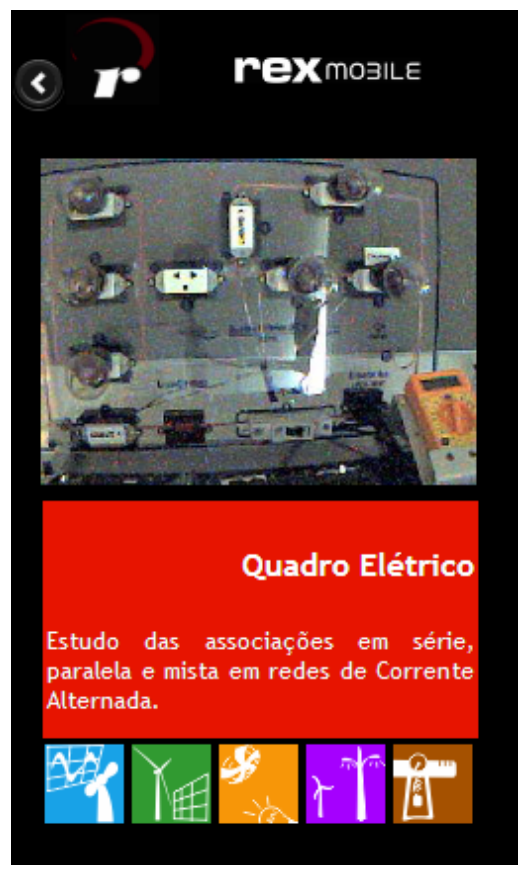

Figure 1. Screenshot of the Experiment Remote 'Electric Panel' in a Smartphone

shared with many other tasks. Inside the production for remote experimentation, it is essential to organize a mental model of data, functions and specific activities, in order for the student to understand and recognize these elements [8].

\section{NEED FOR INTERACTIVE ENVIRONMENTS IN EDUCATIONS}

The New Information and Communication Technologies (NICTs) allow the creation of spaces for human interactions enabling new processes of learning, communication and knowledge construction.

They have been incorporated to education in different scenarios giving rise to a wide range of uses. He is currently a topic of current discussion on the incorporation interconnected computing devices, and directly associated with the ability of NICTs to network interconnection and intercommunication, which in turn relate to the creation of new teaching and learning environments, ie discusses, in particular, as the World Wide Web (WWW) may favor the emergence of new teaching and learning environments as this scenario provides that students can build knowledge beyond educational institutions.

The NICTs enable distance learning demonstrating that is no longer the classrooms the unique local knowledge, and offer a dynamic that does not admit the monopoly of the content or the transmission of a data space and time by a single person in possession of knowledge that is, the teacher.

Constantly connected, new forms of teaching are not enough to please the students, not just provide access to the same resource that is commonly available and suitable to a mobile reality, the entire methodology must converge interactively.

In the educational process, the inclusion of mobile devices, can contribute to these methodological changes aimed at boosting models attractive for digital users, because they allow to continue the educational process by making use of small devices that can offer the same features that a computer desktop or laptop. Mobile devices aggregate geographical mobility with the virtual which allows the learning by the time that is needed. From this one can understand Mobile learning as a new form of personal learning that never ends, a new model where technological and pedagogical points to a new dimension in the mold of education that can meet the needs of the learning located in mobile scenarios and allow highly interactive activities.

The Mobile learning should be understood as a component that adds value in the process of teaching and learning as it provides interconnectivity offers freedom, decreases the dependence of place or space and produces capturing thoughts and ideas spontaneously, pushing the boundaries of classrooms, allowing access resources available when and where the user needs, facilitates the possibility to implement innovative ways to teach classes and learning.

\section{INCENTIVES FROM THE USE OF NICT'S}

The application of mobile devices are becoming increasingly accessible to most classes, popularizing access to innovative technological resources and values not very high, and the incentives such as tax exemptions for tablets, announced by the government [9], has contributed to this access.

In order to provide access by students to technology, the Ministry of Education and Culture of Brazil (MEC), through the National Program of Educational Technology (ProInfo), has distributed computers, digital resources and educational content for schools, in turn, states and cities ensure infrastructure and training for teachers [9].

As from November 2012, the MEC also began the distribution of tablets to High School teachers [10]. According to the Minister Aloizio Mercadante: "We are advancing into a knowledge society, the digital archives are available on the internet, so is need to insert teachers and the school this context. We have this challenge. ".

Tablets tend to quickly reduce prices with tax incentives and bulk buying by the government, thus, lower social classes will have access to the resource and take advantage of new technologies.

You cannot count on major processes in these devices, so access to learning environments should be facilitated by interacting with the touchscreen features and some options with the accelerometer, it makes it more enjoyable to use that aims to attract students' attention to possibilities that new technologies offer.

These incentives tablets in education are not only in Brazil, the government of Thailand will also distributing tablets in schools [11].

Already there are tablets made with the purpose of use in education, CES2012 was presented the tablet from One Laptop Per Child (OPLC) [12], made for children in school, will cost US\$100 and includes adaptations as the rubber cover for protection.

\section{IV.ADEQUACY OF VLE FOR TEACHING AND LEARNING IN MOBILE DEVICES}

The ubiquity, the main feature of the model applied to M-learning, i.e. learning anywhere and anytime [3], allows you to extend the boundaries of the classroom. The 
use of specific technologies is what differentiates it from other learning machines, where the mobile device allows for learning while on the move [13].

The user is looking for objectivity, however note a dispersion very easy to use the internet as a resource for education due to frequent use of social networks, instant messaging, e-mail, games or other diversions also is used as a mobile device, other tasks are performed simultaneously losing focus.

Thus, the mere availability of learning materials for mobile devices is not enough, you need to make them suitable for this type of education, providing different distractions and little time, a nice feature is being able to stop at any time and continue studies another time at the same spot that had been pending, or else skip stages and take control of pending tasks.

Another concern is about the configuration of devices such as operating system, touchscreen, screen size, storage capacity, performance, Internet access or resources accelerometer, compass, location and vibration, because the user may be frustrated with the limitation of resources available if your device does not fit to a proposed standard. For this there are standards for development as indicated by the W3C as fig. 2 .

By allowing this easy availability, it is possible to reach more users and provide a pleasant experience and not frustrated with their devices. Thus, interfacing with the user should be facilitated, fulfilling the role of informing the necessary and for this, we observe the behavior of the application in the projection data entry reduced, due to limitation of size keyboard on devices.

With memory limitations is important to check the information to see what is really necessary in small screen content and reduce long in order to not consume too much bandwidth by the cost per byte, in some connections. The colors also influence the affection for the application, the excess can make the look heavy and tiring.

For this purpose it is important to note the support of new languages that enable integration features interactive and portable to other mobile devices, since even a short time ago, the development behaved differently for each platform being required by an adaptation unit.

Moreover, other factors have also encouraged this creation with high investments in network infrastructure, greater coverage area, reducing costs, availability, technological resources and good user acceptance.

\section{Mobile Telephony Network}

The preview of the experiments require a good internet access due to streaming video, this access can be provided by the use of third generation technologies and mobile telephony standards, with speeds compared to Broadband and allows for a good connection speed.

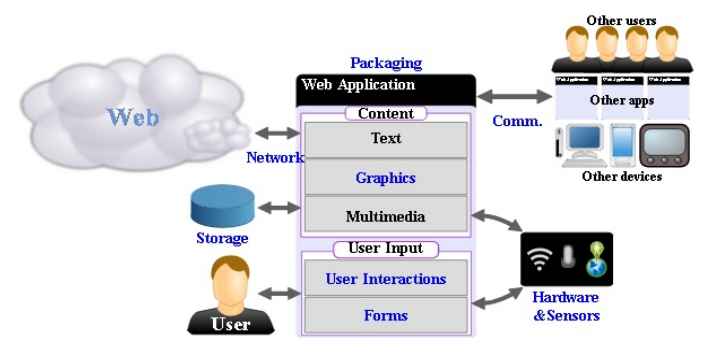

Figure 2. The Web as a platform for application development [14].
There is a rapidly expanding $3 G$ mobile network access and high investments for $4 \mathrm{G}$ network infrastructure in Brazil, driven by the 2014 World Cup and 2016 Olympics, Us\$ 6 billion will be spent on procurement and infrastructure [15], which includes extending a submarine fiber optic cable to the United States, with this expansion the companies intend to offer service packages. Several points of free internet are also being deployed to the lowincome people can access the World Wide WEB in order to popularize access to information.

The idea is that by expanding the study site and interactivity with the devices, students can review a topic before class or interact with the experiments in different locations, perhaps sharing with colleagues and family demonstrating the experiences and knowledge acquired.

\section{TEACHING MATERIAL}

Pereira [16] describes the Virtual Learning Environment (VLE) as a media option used to mediate the learning process from a distance. The RExLab uses the Modular Object-Oriented Dynamic Learning Environment (Moodle ${ }^{2}$ ), a VLE open source and free which enables the development of dynamic websites, as well, to share educational content, features like chat, forums and custom activities in different modes questionnaires. These possibilities offered by Moodle facilitate the production and distribution of teaching materials, resources integrated with a database MySQL also allows for learning management, student assessment, access control and pedagogical support.

The Mobile Learning Engine plugin for Moodle (MLEMoodle) module is also open source, freely offered and customizable features that allow access to Moodle, being installed on the same server without the need to install any additional feature on the mobile device.

This plugin provides the adaptation layer that interacts with the proposed Pereira [16] in situations:

- Documentation and Information: download and upload files, supporting the use of AVA and presentation of adapted teaching material, content and institutional information.

- Communication: Adaptation of information synchronously and asynchronously with respect to the need of the device.

- Pedagogical and administrative management: different profiles for access and visualization of performance evaluations or queries, depending on the type of user.

- Production: development and resolution of problems or activities within the environment.

A wide range of settings and diversification of resources available, require specific adaptations, this line, the implementation of the mobile portal RExlab with the MLE-Moodle allows users with different mobile devices to access the Web interface without the restriction of the operating system, this allows you to access the experiments, conduct their studies and complete their activities, without requiring powerful devices.

The educational material that can be downloaded from RExLab on mobile devices are in Portable Document Format (.PDF) and PowerPoint presentations (.PPT) formats that most mobile devices can view and accommodate the different screen formats. These contents are not

${ }^{2}$ Available at: http://rexlab.ararangua.ufsc.br/moodle/ 
easy to become bored reading, highlighting the most important points and providing examples.

Another interesting feature that can facilitate the sharing and availability of online content is the QR-code, a 2D barcode that when scanned, it is converted to a link, Fig 3.

Another concern about the teaching material available is objectivity, because the user does not usually stay long periods with the device in his hands and concentration right now is shared with many other tasks. Within the production for remote experimentation, it is essential to organize a mental model of data, functions and specific activities in order the student to understand and recognize these elements.

\section{EXPERIMENTS REMOTE INTERACTIVE}

The experiments are remote physical elements that interact with activated commands remotely via web in experiments related to microservers Web or Arduino boards with ethernet port [17]. Thus, the interactions are direct with real equipment controlling relays, circuits or sensors, and get the real-time feedback of the results of online experiences, observing them through streaming video from an IP camera directed.

How important technological still attractive, the touchscreen interface adapted to provide better control and greater reality, even mediated distance. The simplest devices already have this feature, and easily adapted to interfaces that use the mouse to interact [18].

A practical and interactive, with proper layout attracts attention to the study and in this case, relating to real experiments, tends to increase interest throughout the technology involved, taking control of these phenomena hitherto seen only in theory. And yet, allow the demonstration of more concepts studied in science classes in the classroom and the practical advantages of understanding them, benefiting student learning.

\section{DEVELOPMENT APPLICATION FOR THE PROPOSED METHODOLOGY}

From these topics presented and the importance of allowing easy access to the greatest number of users at any place and any time, the creation of RExMobile for interaction experiments in remote labs, one realizes the need to integrate technologies and languages that encourage use.

In this regard, it is notable progress in language development and HTML5 (Hypertext Markup Language version 5), which allows enjoy great features of the devices, further immersing the user, ensuring easy portability to different devices. This development is expanding rapidly with intense encouragement has allowed the development of new attractive tools to use.

Another interesting feature is the definition of styles with CSS3 (Cascading Style Sheets, version 3) for pages developed with this language variant of XML (Extensible Markup Language) you can create patterns of light and good looks.

These interesting development resources are integrated by the jQuery Mobile framework, which employs a unified system suitable for Web applications on mobile devices [19] and with the use of high-level JavaScript, generating code compatible with iOS, Android, Windows Phone, Symbian, BlackBerry, and other major mobile operating systems.

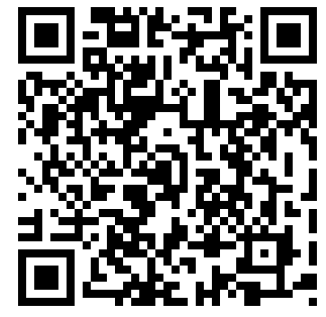

Figure 3. QR-Code for access at RExLab portal
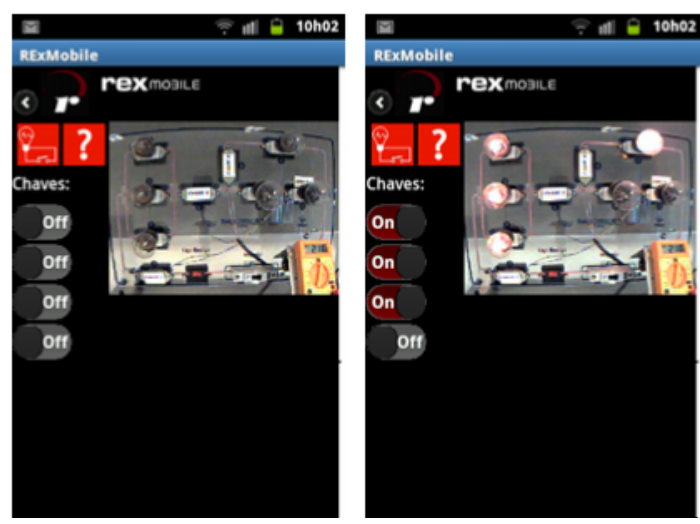

Figure 4. Interaction with remote experiment application on a Samsung S8530i with Android 2.3 OS

A further facilitated by the creation of resources ThemeRoller tool that allows for the definition of these patterns online. Tools that ensured useful patterns for application development.

Besides these features, we use a JavaScript code that submits commands CGI (Common Gateway Interface) Microserver coupled to the experiment, activating it and allowing visualization of the effects through a streaming video in JPEG, also bearable in different mobile platforms.

Finally, the application allows access to activities and teaching material available in Moodle. This way, the student learns the theory with content specific to the study of physical effects related to experiment, interact and visualize the effects that occurred with this and still conducts its business through mobility.

\section{CONCLUSION}

In this model, we intend to contextualize the experience and learning, making the study more attractive, focusing on teaching application, while requiring constant access that expand the playing field and benefit the discipline beyond the barriers of class, differentiating the simple use of virtual labs that simulate only the experience and not interact with real equipment, where the manipulation of results or experiences not faithfully reproduce reality.

The advantage of using Remote Laboratories focused on the educational environment with the development of targeted experiments, added to teachers' participation and collaboration of students, allows utilities to better design productivity of education, making it more efficient and applicable to everyday life, as a way the cover further needs. From the device with internet access, students can access anytime experiences available in the labs, interact with real equipment and check the concepts studied in class into practice, to relate knowledge with the observation of the experiments. 
This relationship streamlines thus the use of internet in schools, not only as an underutilized resource for research, but as a tool useful to interdisciplinary teaching and learning and develop their own concepts. It also encourages students to pursue the study of scientific and technological areas by implementing activities that relate the theoretical concepts to practical usability and linking these areas of science. According to Antunes [20]:

"[...] Learning contributes to personal growth because who truly learns not copy or reproduce the reality, before learning when it is able to develop a personal representation of an object or content of reality that seeks to know."

Therefore, the Virtual learning environments and remote experimentation present themselves as reputable tools for the teaching-learning collaborative, coverage with access from mobile devices allows even more opportunities for this appealing and interactive teaching. They offer an interesting perspective for teaching social and collaborative and distributed across multiple applications. These new technologies can promote a high degree of immersion, providing a sense of real presence and communication anywhere.

Therefore, the advantage of using the Mobile Learning Labs, the intended use of the equipment to better productivity in teaching, assigning more efficiently and applied to daily life, which includes further needs. Thus, students can access anytime experiences available in laboratories and compose the concepts studied in class, associating knowledge with the observation of the experiments.

The motivation of this project is to develop efficient methodologies and attractive through virtual learning environments and remote experimentation, adapted to these mobile devices. The application through research, development and implementation allows to provide an architecture based on the use of educational NICTs as support for these solutions cost effectively, taking into account the cognitive and pedagogical aspects of teaching and learning process.

\section{REFERENCES}

[1] E.C.J. Araujo et, (2012, mar) Evaluate the usability of mobile devices. Scientific Journal of the Institute for Specialized Education of Paraíba. [Online] 2. Available: http://www.fatecjp.com.br/ revista/artigo06.pdf.

[2] S. Paladini, J.B. Silva, J.B, G.R. Alves; B.T. Fischer and J.B. Alves. "Using Remote Lab Networks to Provide Support to Public Secondary School Education Level". presented at 11th IEEE International Conference on CSEWORKSHOPS '08. Computational Science and Engineering Workshops. São Paulo, SP, 2008.

[3] D. Dochev; I. Hristov. Mobile Learning Applications Ubiquitous Characteristics and Technological Solutions. Bulgarian Academy Of Sciences Cybernetics And Information Technologies, vol.6, no 3, Sofia, 2006.

[4] M.C.Krause,, P.M.Mozzaquatro, Arsha: Object of mobile learning adapted defaults of usability and accessibility .Exhibit II Scientific Initiation of Computer Science. [Online]. 5.Available: http://www.ctec.unicruz.edu.br/labins/JAC2011/artigos/arsha objet o_de_aprendizagem_movel_adaptado_a_padroes_de_usabilidade_e acessibilidade.pdf

[5] M. Sharples. Disruptive Devices: Mobile Technology for Conversational Learning. International Journal of Continuing Engineering Education and Lifelong Learning, 12, 5/6, pp. 504-520, 2003. http://dx.doi.org/10.1504/IJCEELL.2002.002148

[6] Mobile Web Application Best Practices, W3C [Online]. Available: http://www.w3.org/TR/2010/REC-mwabp-20101214/.

[7] A. C. Pereira, "Virtual learning environments" in Virtual learning environments in different contexts, 1th, Ed. Ciência Moderna, Rio de Janeiro, RJ, 2007, pp. 5.
[8] T.Pagani, (2012, mar) "Usability of interfaces for mobile devices: What changes in usability issues when we are talking on mobile devices?" (1 ed.) [Online]. Available: http://tableless.com.br/ usabilidade-de-interfaces-para-dispositivos-moveis-parte1/

[9] ProInfo (2013, feb) National Program of Educational Technology [Online] Available: http://portal.mec.gov.br/index.php?option=com content\&view=article\&id=244\&Itemid=462

[10] Fundo Nacional de Desenvolvimento da Educação (2012, nov) "Minister delivery tablets and has initiated training of coordinators" [Online] Available: http://www.fnde.gov.br/fnde/sala-de-imprensa/ noticias/item/3917-ministro-entrega-tablets-e-tem-in\%C3\%ADcioa-forma\%C3\%A7\%C3\%A3o-de-coordenadores

[11] F. Morales (2011 nov) "Thai Government will distribute tablets in schools" [Online] Available: http://henrique.geek.com.br/posts/ 18279-governo-tailandes-distribuira-tablets-em-escolas

[12] B. Crothers (2012 jan) "\$100 OLPC tablet to debut at CES" [Online] Available: http://ces.cnet.com/8301-33363 1-57354391/ \$100-olpc-tablet-to-debut-at-ces/

[13] V. F. Bartholo, M. A. Amaral and M. I. Cagnin "A Contribution to Adaptalidade of Virtual Learning Environments for Mobile Devices" Revista Brasileira de Informática na Educação. V 17, n2, 2009.

[14] A. Connors and B. Sullivan (2010 dec) "Mobile Web Application Best Practices" [Online] Available: http://www.w3.org/TR/2010/ REC-mwabp-20101214

[15] Portal Brasil (2012 dec) "4G technology is launched and marketed in Brazil" [Online] Available: http://www.brasil.gov.br/noticias/ arquivos/2012/12/17/tecnologia-4g-e-lancada-e-comercializada-nobrasil

[16] A. T. C Pereira and V. A. C. Schmitt "Virtual Learning Environments". Pereira, A.T.C. (Org), in AVA -Ambientes Virtuais de Aprendizagem em diferentes contextos. Rio de Janeiro: Editora Ciência Moderna. 2007. Cap.1, p. 4-22. http://dx.doi.org/10.1186/ 1753-2000-1-4

[17] J. B. Silva "The Use of Remote Experimentation as support for collaborative learning environments" Florianópolis: UFSC, 2007, Master Thesis.

[18] R. J. Costa and G. R. Alves "Mobile Experimentation innovating education to the 'mobile phone' generation" [Online] Available: ave.dee.isep.ipp.pt/ rjc/Docs/2006/ECUMICT06/paperECUMICT $\underline{\text { 06.pdf }}$

[19] M.S Silva "jQuery Mobile - Develop web applications for mobile devices with HTML 5, CSS\#, AJAX, jQuery e jQuery UI". São Paulo: Novatec, 2012

[20] C. Antunes. "New Ways of Teaching. New Ways to Learn" Porto Alegre: Artmed, 2002. 172 p.

\section{AUTHORS}

Willian Rochadel, is an Academic at Federal University of Santa Catarina (UFSC) and administrative staff, Araranguá, Brazil. (willian.rochadel@ufsc.br)

Juarez Bento da Silva, is a researcher at Federal University of Santa Catarina (UFSC), Araranguá, Brazil. (juarez.silva@ieee.org).

José Pedro Simão, is an Academic at Federal University of Santa Catarina (josepedrosimao@gmail.com).

Gustavo Ribeiro Alves is a full Professor at the Polytechnic of Porto, School of Engineering (IPP/ISEP), (gca@isep.ipp.pt)

Roderval Marcelino, is a researcher at Federal University of Santa Catarina (UFSC), Araranguá, Brazil (roderval.marcelino@ufsc.br).

Vilson Gruber, is a researcher at Federal University of Santa Catarina (UFSC), Araranguá, Brazil. (vilson.gruber@ufsc.br).

This article is an extended and modified version of a paper presented at the International Conference on Remote Engineering \& Virtual Instrumentation (REV2012), held at University of Deusto, Bilbao, Spain, July 4-6, 2012. Received 23 february 2013. Published as resubmitted by the authors 20 March 2013. 